У контексті управління інічіацією проектів виконаний аналіз особливостей та узагальнення оцінки ступеню досконалості виробничих систем і показано, що ия ступінь може бути відображена через узагальнений показник рівня існуючого в об'єкті ризику. Феноменологічним відображенням ризику для організаційно-технічних систем є ланщюги Маркова. Досліджені практичні аспекти оцінки ефективності ініціації та впровадження проектів в умовах діючого підприємства

Ключові слова: інічіація проектів, охорона прачі, ступінь досконалості, ризик, оцінка, ланциюги Маркова

В контексте управления инищиацией проектов выполнен анализ особенностей и обобщение оценки степени совершенства производственных систем и показано, ито эта степень может быть отражена через обобщенный показатель уровня существующего в объекте риска. Феноменологическим отражением риска для организационно-технических систем является цепи Маркова. Исследованы практические аспекты оценки әффективности инициации и реализации проектов в условиях действующего предприятия

Ключевые слова: инициация проектов, охрана труда, степень совериенства, риск, оценка, цепи Маркова

\section{DEVELOPING A SYSTEM FOR THE INITIATION OF PROJECTS USING A MARKOV CHAIN}

\author{
V. Gogunski \\ Doctor of Technical Sciences, Professor*
}

E-mail: vgog@i.ua

A. Bochkovski

PhD, Assistant Professor*

E-mail: andrew.bochkovsky@gmail.com

A. Moskaliuk

$\mathrm{PhD}^{*}$

E-mail: Andreum@mail.ru

O. Kolesnikov

$\mathrm{PhD}$, Assistant Professor*

E-mail: akoles@list.ru

S. B a b i u k

$\mathrm{PhD}$, Associate Professor*

E-mail: sergiy.babyuk@gmail.com

*Department of Systems Management Life Safety

Odessa National Polytechnic University

Shevchenko ave., 1, Odesa, Ukraine, 65044
Transition to the project-oriented management of enterprises with regard to international principles about the organization of production is carried out through the creation, implementation and improvement of informational tools for supporting the processes of project initiation [1]. In many businesses and organizations, a significant share of their activities has a project character, especially in the provision of safe working conditions [2].

Initiation of projects on safety is based on comprehensive assessment of the level of hazard of industrial objects. Decision making on the initiation of projects implies an assessment of working conditions and the implementation of certain measures to improve labor protection. These measures define the needs for new equipment, technology, and technical-engineering means of safety. In this case, the problem of resolving social and everyday problems is always taken into account [3].

Two constituents predetermine the relevance of research presented in the article. First, an information-analytical management system is developed for the organizational-technical object, which engages the enterprise's employees in the management contour. Second, by applying a Markov model, we perform an assessment of the level of perfection of the object that makes it possible to solve the task on improving production system through the initiated projects.
2. Literature review and problem statement

The difficulties in the initiation and management of projects in organizational-technical systems are caused by the existence of a set of factors and their mutual dependence [4]. Such systems lack models and methods for the representation of information about the dynamics of processes [5]. The turbulence of environment and variability in the nature of processes over time does not allow us to select and examine in detail individual elements of the system [6]. The indicated peculiarities predetermine a necessity for studying phenomena in the organizational-technical systems, not by separate elements but for the project as whole [7].

Due to the indicated peculiarities, projects are weakly structured systems [8]. A set of factors of the system creates a complex "web" of connections and states, causes and consequences that change over time [9]. The development and progress of projects in such multifactorial weakly structured system is not deterministic. Therefore, for the description and simulation of trajectory of the development of projects in the phase space of probabilities of states, it is proposed to apply phenomenological models [10]. The class of phenomenological models includes Markov chains that allow representation of the connection between the output and input parameters without taking into account the physical essence of processes in the system. Markov chains reflect the structure of projects and are "configured" for certain 
projects through determining the transition probabilities between states based on practical data [11].

A formation of the modern paradigm for creating conditions of safety in industry is due to the adoption by international community of a series of international standards in the field of quality management, labor safety, environmental management and social responsibility [3]. Over the last few years, the problems on creating safe working conditions have become a popular subject of research and practical applications in the world. A search within the scientific-metrical base Google Academy for key words "Occupational health and safety projects" revealed hundreds of millions of web pages (Table 1).

Table 1

Number of web pages when searching within Google Academy for key words "Occupational health and safety projects"

\begin{tabular}{|c|c|c|}
\hline Search attributes by key words & $\begin{array}{c}\text { Search } \\
\text { language }\end{array}$ & $\begin{array}{c}\text { Number of web } \\
\text { pages, mln. }\end{array}$ \\
\hline $\begin{array}{l}\text { (Occupational health and safety } \\
\text { projects) \& USA }\end{array}$ & en & 110,1 \\
\hline भारत में आजीवन सीखने (India) & in & $56,3^{(1)}$ \\
\hline $\begin{array}{c}\text { (Occupational health and safety } \\
\text { projects) \& India }\end{array}$ & en & $16,4^{(1)}$ \\
\hline $\begin{array}{l}\text { (Occupational health and safety } \\
\text { projects) \& England }\end{array}$ & en & 76,7 \\
\hline $\begin{array}{l}\text { (Occupational health and safety } \\
\text { projects) \& China }\end{array}$ & en & $33,4^{(2)}$ \\
\hline 终身学习在中国 (China) & $\mathrm{cn}$ & $1,46^{(2)}$ \\
\hline $\begin{array}{c}\text { (Occupational health and safety } \\
\text { projects) \& Germany }\end{array}$ & en & $29,9^{(3)}$ \\
\hline $\begin{array}{c}\text { (Arbeitssicherheit und } \\
\text { Gesundheit) \& Deutschland }\end{array}$ & de & $0,369^{(3)}$ \\
\hline $\begin{array}{c}\text { (Projets en santé et sécurité au } \\
\text { travail) et en France }\end{array}$ & fr & 26,6 \\
\hline $\begin{array}{l}\text { (Occupational health and safety } \\
\text { projects) \& Japan }\end{array}$ & en & $25,3^{(4)}$ \\
\hline 労働安全衛生プロジェクト(Japan) & jp & $6,37^{(4)}$ \\
\hline $\begin{array}{c}\text { (Occupational health and safety } \\
\text { projects) \& Russia }\end{array}$ & en & 18,3 \\
\hline $\begin{array}{l}\text { (Occupational health and safety } \\
\text { projects) \& Korea }\end{array}$ & en & 16,2 \\
\hline $\begin{array}{c}\text { (Proyectos de salud y seguridad en } \\
\text { el trabajo) \& España }\end{array}$ & es & 10,4 \\
\hline $\begin{array}{c}\text { (Occupational health and safety } \\
\text { projects) \& Indonesia }\end{array}$ & en & 8,11 \\
\hline $\begin{array}{l}\text { (Occupational health and safety } \\
\text { projects) \& Ukraine }\end{array}$ & en & $6,19^{(5)}$ \\
\hline $\begin{array}{c}\text { (Проекти з охорони праці) \& } \\
\text { Україна } \\
\end{array}$ & ua & $1,2^{(5)}$ \\
\hline $\begin{array}{c}\text { (Projets en santé et sécurité au } \\
\text { travail) \& Kanada }\end{array}$ & fr & $3,08^{(6)}$ \\
\hline $\begin{array}{l}\text { (Occupational health and safety } \\
\text { projects) \& Kanada }\end{array}$ & en & $1,43^{(6)}$ \\
\hline
\end{tabular}

Note: $(N)$ - grouped data in different languages for one country $N$

It is clear that these projects had to be prepared for the implementation through their initiation.

In the case of initiation, an idea of the project is transformed into the vision of the project. It is the vision of the project that implies building up a correct model of the project, as well as the product of the project. At this stage, available methods and means for the transformation of resources into products/services under conditions of existing constraints are selected, and requirements to the level of competencies of project team are created [12].

Project decisions at this stage are worked out in the cooperation from all stakeholders of the project [13]. Practical transition to the implementation of the project-led management with regard to the global nature of the problem should be carried out based not on the intuitive solutions, but based on the theoretical prerequisites, essence, regularities and laws $[8,14]$.

Resolving contradictions between the requirements to the efficiency of systems for the initiation and management of projects and tasks on supporting project decision making is possible through the use of information systems [15]. Known mathematical models do not make it possible to represent parameters of the projects that are not available for direct measurement $[16,17]$. Research is scientifically and practically important since it is aimed at solving relevant problem of project management. The essence of the problem is in the creation of feedback between a managed object and the community of employees. The feedback is implemented using the surveys from the community of employees. This is what enables adjusting a Markov chain to the description of a particular object [18].

A representation by using Markov chains of technical or social systems is based on the structural and parametric similarity of the originals of these systems with their representations - Markov models [2]. The peculiarities of implementing the paradigm of "lifelong learning" were investigated due to the cognitive properties of Markov chains in article [10]. The development of a Markov model for the activity of an engineer on labor safety was carried out in paper [11]. Article [14] presents, using a Markov model, an organizational-technical system of changes in the conditions of patients in the projects for the provision of medical services. General questions on modeling the project management by using a Markov models are highlighted in [16]. One can also note the effectiveness of applying Markov models to assess quality of an educational institution [18]. The mentioned examples are combined by the existence of decomposition of the examined systems into certain discrete states with the construction of a graph for the transitions between these states. The differences in the mentioned models manifest themselves in various approaches for determining conditional transition probabilities between discrete states. That is, the identification of Markov chains with discrete states and time to represent various objects is determined by the methods for computing the transition probabilities [8].

\section{The aim and tasks of the study}

The aim of the study is the development of information-management system for the assesment and initiation of projects using a Markov chain.

To achieve the set aim, the following tasks were to be solved:

- to develop a model for assessing the level of perfection of organizational-technical system based on a Markov chain by discrete states that reflecting the degrees of risk of the system: $\mathrm{R}_{1}-$ low risk; $\mathrm{R}_{2}-$ medium risk; $\mathrm{R}_{3}-$ high risk; $\mathrm{R}_{4}$ - extreme risk;

- to devise a technique for the identification of a Markov model by conducting a survey that will enable "tuning" 
the Markov chain to represent the properties of a specific object;

- to perform the formalization and improvement in the tool provision of the initiation of projects with the construction of a general basic management scheme, in which Markov model is a part of the control loop;

- to explore practical aspects in evaluating effectiveness of the initiation and implementation of projects under conditions of actual enterprise.

\section{Creating a model for evaluating the level of perfection of the production system}

Let us accept a hypothesis on that the degree of perfection of any production system can be represented using a generalized indicator of the system quality, which corresponds to the level of risk that existing within the object. We shall understand risk to be the level of uncertainty in events or conditions whose occurrence negatively or positively affects the goals of activity $[17,19]$.

The cause of risk occurrence may include a set of factors, namely:

- working conditions in the workplace;

- shortcomings of organizational-technical character;

- external natural factors;

- psychological climate with the collective;

- engineering and technical means of safety;

- sanitary conditions, etc.

An assessment of the degree of perfection for such systems, as a rule, can be performed only by using phenomenological representations. One of these approaches is the application of Markov chains.

We shall represent a model for evaluating the level of perfection in an organizational-technical system in the form of four discrete states, which correspond to possible probabilistic estimations of the degree in risk of the system: $\mathrm{R}_{1}$ - low risk; $\mathrm{R}_{2}$ - medium risk; $\mathrm{R}_{3}$ - high risk; $\mathrm{R}$ - extreme risk. To construct a Markov model for the transitions of estimations in the risk degree as the states of production systems at an enterprise, we shall define basic transitions between these states (Fig. 1).

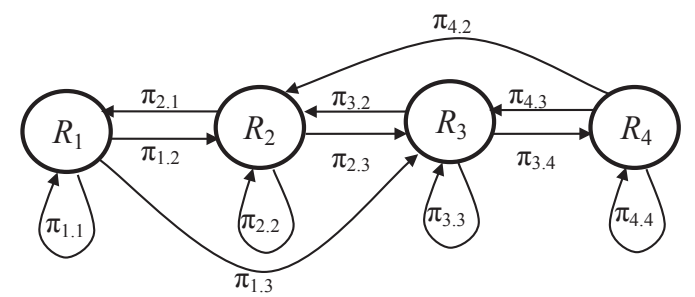

Fig. 1. Marked graph of a Markov chain that represents the levels of perfection in the organizational-technical system with transitions of the risk degree assessments between states of the system

General solution for a system of equations that describe the Markov chain, presented in Fig. 1, can be written down in the form [16]:

$$
\left\|\begin{array}{l}
\mathrm{p}_{1}(\mathrm{k}+1) \\
\mathrm{p}_{2}(\mathrm{k}+1) \\
\mathrm{p}_{3}(\mathrm{k}+1) \\
\mathrm{p}_{4}(\mathrm{k}+1)
\end{array}\right\|^{\mathrm{T}}=\left\|\begin{array}{l}
\mathrm{p}_{1}(\mathrm{k}) \\
\mathrm{p}_{2}(\mathrm{k}) \\
\mathrm{p}_{3}(\mathrm{k}) \\
\mathrm{p}_{4}(\mathrm{k})
\end{array}\right\|^{\mathrm{T}}\|\cdot\| \begin{array}{cccc}
\pi_{1.1} & \pi_{1.2} & \pi_{1.3} & 0 \\
\pi_{2.1} & \pi_{2.2} & \pi_{2.3} & 0 \\
0 & \pi_{3.2} & \pi_{3.3} & \pi_{3.4} \\
0 & \pi_{4.2} & \pi_{4.3} & \pi_{4.4}
\end{array} \|,
$$

where $\mathrm{T}$ is the sign of transposition of columns; $\pi_{\mathrm{ij}}$ are the transition probabilities.

The sum of probabilities of all the states $p_{i}(k)$ at each step $\mathrm{k}$ is equal to unity [18]:

$$
\sum_{\mathrm{i}=1}^{\mathrm{m}} \mathrm{p}_{\mathrm{i}}(\mathrm{k})=1
$$

where $\mathrm{p}_{\mathrm{i}}(\mathrm{k})$ is the probability of ith state in step $\mathrm{k}$; $\mathrm{i} \in$ $\in(1,2, \ldots, m=4)$.

By step k we understand a certain controlling influence that pushes the system into new state [18].

The amount of transition probabilities $\pi_{\mathrm{ij}}$ from certain state $i \in(1,2, \ldots, m)$ into other states $j \in(1,2, \ldots, m)$ is equal to unity [14]:

$$
\sum_{\mathrm{j}=1}^{\mathrm{m}} \pi_{\mathrm{ij}}=1, \quad\{\mathrm{i}=1,2, \cdots, \mathrm{m}\},
$$

where $m=4$ is the number of possible states of the system.

If one defines all the $\pi_{\mathrm{ij}}$ elements in the transition probabilities matrix and accepts the values of initial probabilities of states $\left\{\mathrm{p}_{1}(\mathrm{k}), \mathrm{p}_{2}(\mathrm{k}), \ldots \mathrm{p}_{4}(\mathrm{k})\right\}$ in a uniform Markov chain, the values of probabilities of states $\left\{\mathrm{p}_{1}(\mathrm{k}+1)\right.$, $\left.\mathrm{p}_{2}(\mathrm{k}+1), \ldots \mathrm{p}_{4}(\mathrm{k}+1)\right\}$ in the next $\mathrm{k}+1$ step are determined from a system of equations (1) that describe the Markov chain, shown in Fig. 1.

Thus, for "tuning" a Markov chain with discrete states and time to represent the properties of specific systems, it is necessary to determine all $\pi_{\mathrm{ij}}$ elements in the matrix of transition probabilities between various states [8].

\section{Technique for the identification of a Markov model by determining experimentally the transition probabilities}

To perform the set task, we used a method for direct calculation of states $R_{i}$ based on data on surveys of employees (the enterprise "Geleka-M", Odessa, Ukraine) with the subsequent solution of inverse problem on finding $\pi_{\mathrm{ij}}$ values of transition probabilities by the Monte Carlo method. At this stage, we set the goal to solve the following tasks:

- working out unambiguous questionnaire;

- defining convenient procedure for the survey;

- devising methods for the estimation of error in results;

- determining a sample scope.

The most effective are survey sheets (questionnaires) in which responses are reduced to unambiguous simple affirmations: Yes/No. The questions in the questionnaire were formulated in the following form:

a) how many times did you receive information from different sources regarding labor safety at the enterprise $(k)$;

b) how do you assess risk at the enterprise (please choose only one option)

$\begin{array}{ll}\text { - low risk } & \text { (yes); } \\ \text { - medium risk } & \text { (yes); } \\ \text { - high risk } & \text { (yes); } \\ \text { - extreme risk } & \text { (yes). }\end{array}$

As a result of the survey, in each questionnaire we obtain value of step $k$ and one of the values $R_{i}\{i=1,2,3,4\}$. Processing results of the survey comes down to grouping the results by steps $\mathrm{k}$. Then we define experimental values of frequency of each state in the form of ratio of the number of separate states to the total number of questionnaires in kth group. 
The values of transition probabilities $\pi_{\mathrm{ij}}$ are found by solving the inverse problem of searching for values of transition probabilities by the Monte Carlo method [18].

Experimental verification of the questionnaire revealed that respondents often were unable to give a specific answer to the first question (a). It was therefore proposed to use another variant of this question in a fuzzy form:

a) how many times did you receive information from different sources regarding labor safety at the enterprise $(\mathrm{k})$.

If you do not remember, please choose one of the options:

- I have never heard;

- several times (to 5);

- many times (to 10);

- more than 10 times.

Respondents answered such questions more confidently.

\section{1. Determining a sample size}

The minimum number $\mathrm{n}$ of questionnaires that provides for the selected accuracy of measurements can be defined by accepting normal law of random variables distribution and maximum standard error of the estimation. Then, using the expressions known from mathematical statistics, one can determine the minimum number $\mathrm{n}$ of questions that allows for the required accuracy of measurement.

Interval estimation of error in the surveys is carried out based on statistical data using confidence probability. For the normal data distribution law and extensive sample $(n>30)$, total estimating characteristic of measurements is variance $\mathrm{D}$ and coefficient of variation $\mathrm{k}_{\mathrm{v}}$ :

$$
\begin{aligned}
& \mathrm{D}=\sigma^{2}=\frac{1}{\mathrm{n}-1} \sum_{\mathrm{i}=1}^{\mathrm{n}}\left(\mathrm{x}_{\mathrm{i}}-\overline{\mathrm{x}}\right)^{2} ; \\
& \mathrm{k}_{\mathrm{v}}=\frac{\sigma}{\overline{\mathrm{x}}},
\end{aligned}
$$

where $x_{i}$ is the value of parameter that is evaluated, $i=$ $=1,2, \ldots, \mathrm{n} ; \overline{\mathrm{x}}$ is the arithmetic average of the value of the parameter.

Confidence interval describes the interval of values $\mathrm{x}_{\mathrm{i}}$, which includes true value $x_{d}$ of the measured magnitude with the assigned probability $\mathrm{p}_{\mathrm{d}}$ :

$$
\mathrm{p}_{\mathrm{d}}=\mathrm{p}\left[\mathrm{a} \leq \mathrm{x}_{\mathrm{d}} \leq \mathrm{b}\right]=\frac{1}{2}[\phi(\mathrm{b}-\overline{\mathrm{x}}) / \sigma-\phi(\mathrm{a}-\overline{\mathrm{x}}) / \sigma]
$$

where $\varphi(t)$ is the Laplace integral function, which is determined by tabular data obtained as a result of solving integral:

$$
\phi(t)=\frac{2}{\sqrt{2 \pi}} \int_{0}^{t_{1}} \mathrm{e}^{\frac{-\mathrm{t}^{2}}{2}} \mathrm{dt} .
$$

The ratio of magnitude $\mu=\mathrm{b}-\overline{\mathrm{x}}$ to the R.M.S. deviation $\sigma$ is the argument of this function:

$$
\mathrm{t}=\mu / \sigma
$$

where $t$ is the security factor.

If we adopt confidence probability $\mathrm{p}_{\mathrm{d}}$ (most often, values $0.9 ; 0.95 ; 0.9973$ are taken), then the accuracy of measurements (confidence interval $2 \mu$ ) is determined based on relation $\mathrm{p}_{\mathrm{d}}=\varphi(\mu / \sigma)$. A half of the confidence interval is equal to:

$$
\mu=\sigma \cdot \arg \varphi\left(p_{d}\right)=\sigma t,
$$

where $\arg \left(\mathrm{p}_{\mathrm{d}}\right)$ is the Laplace function argument, and at $\mathrm{n}<30$ - of the Student function.

Based on the accepted level of significance $\left(1-\mathrm{p}_{\mathrm{d}}\right)$, in the case of normal distribution law, one may find $\mathrm{n}_{\min }$ sample, in which error exceeding the confidence interval will occur not more than once:

$$
\mathrm{n}_{\min }=\frac{\mathrm{p}_{\mathrm{d}}}{1-\mathrm{p}_{\mathrm{d}}}
$$

In case when $\mathrm{p}_{\mathrm{d}}$ is equal to 0.95 or 0.9973 , this sample will comprise 19 and 367 measurements, respectively. We accepted confidence probability to be $\mathrm{p}_{\mathrm{d}}=0,95$.

To conduct experimental measurements with the assigned accuracy, it is necessary to know the quantity of measurements, at which the specified confidence level $\mathrm{p}_{\mathrm{d}}=0,95$ is ensured. In this case, the task is reduced to establishing the minimum sample size $\mathrm{N}_{\min }$, at the assigned confidence interval $2 \mu$ and confidence probability. When conducting measurements, it is necessary to know their accuracy:

$$
\Delta=\frac{\sigma_{0}}{\overline{\mathrm{X}}}
$$

where $\sigma_{0}$ is the arithmetic mean value of the R.M.S. deviation $\sigma$, which is equal to $\sigma_{0}=\sigma / \sqrt{\mathrm{n}}$.

The confidence interval of measurement error $\Delta$, similar for measurements, is:

$$
\mu=\sigma \cdot \arg \phi\left(p_{d}\right)=\sigma t=\sigma_{0} / t \sqrt{n} .
$$

In case $\mathrm{N}_{\min }=\mathrm{n}$ we shall obtain

$$
\mathrm{N}_{\min }=\frac{\sigma^{2} \mathrm{t}^{2}}{\sigma_{0}^{2}}=\frac{\mathrm{k}_{\mathrm{B}}^{2} \mathrm{t}^{2}}{\Delta^{2}},
$$

where $k_{v}$ is the coefficient of variation, \%; $\Delta$ is the accuracy of measurements, \%.

Let us accept that $\mathrm{k}_{\mathrm{v}}=2 \%$ and $\mathrm{t}=2.0$ by Laplace for $\mathrm{p}_{\mathrm{d}}=0.95$ and find the dependence of volume of the minimum sample as a function of accuracy of measurement (curve 1, Fig. 2). It is known that the use of this dependence is recommended at $n>30$ measurements. With fewer measurements, they apply the Student distribution. Under the same conditions, let us find the minimum sample, substituting in the formula for calculating $\mathrm{N}_{\min }$, instead of guarantee factor $\mathrm{t}$, the value of the Student coefficient $\alpha_{\text {st }}$ as a function of the number of measurements (curve 2, Fig. 2).

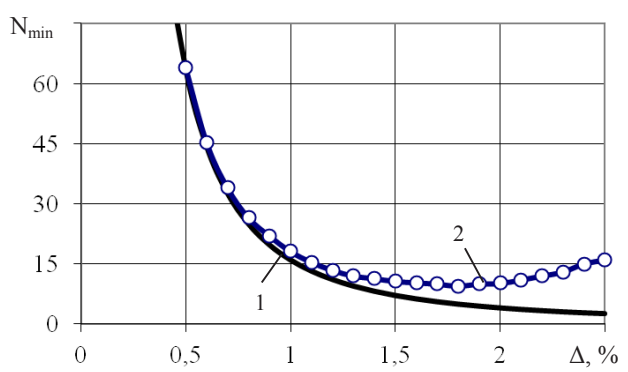

Fig. 2. Dependence of minimum sample $\mathrm{N}_{\min }$ on the assigned measurement error $\Delta$

The obtained data allow us to determine required $\mathrm{N}_{\min }$ minimum sample size. As follows from Fig. 2, in the case 
of 64 measurements, the expected error is not larger than $0.5 \%$. Reduction in the number of measurements leads to increased error. As an acceptable interval of error, one may select values $0.5 \ldots 1 \%$, with a corresponding number of measurements at $64 \ldots 22$. The midpoint of this interval $\sim 0.75 \%$ is provided at 30 measurements. We shall note that from the data of questionnaire survey, only 3 parameters are to be found, while the 4th one, taking into account the fact that all the events comprise a full group, will complement their sum to unity. That is why it is possible to accept the sample size in the quantity of 90 surveys. In this case, the error of values of transition probabilities will not exceed $0.75 \%$.

\section{2. Processing the results of a questionnaire survey}

In accordance with the aforementioned rules for conducting a questionnaire survey and the defined quantity on the recommended sample, we conducted surveying of employees (Table 2).

Table 2

Results of a questionnaire survey

\begin{tabular}{|c|c|c|c|c|c|}
\hline \multirow[t]{2}{*}{$\begin{array}{l}\text { Number } \\
\text { of step }\end{array}$} & \multicolumn{4}{|c|}{$\begin{array}{l}\text { Distribution of surveyed employees at the } \\
\text { enterprise by states, the number of respon- } \\
\text { dents (December, 2014) }\end{array}$} & \multirow{2}{*}{$\begin{array}{c}\text { Total by } \\
\text { steps, } \\
\text { those } \\
\text { surveyed }\end{array}$} \\
\hline & $\mathrm{p} 1$ & $\mathrm{p} 2$ & p3 & $\mathrm{p} 4$ & \\
\hline 0 & 0 & 0 & 2 & 0 & 2 \\
\hline 5 & 2 & 9 & 7 & 6 & 24 \\
\hline 10 & 5 & 13 & 10 & 8 & 36 \\
\hline 30 & 4 & 10 & 8 & 6 & 28 \\
\hline Total & 11 & 32 & 27 & 20 & 90 \\
\hline
\end{tabular}

Based on the obtained experimental data, it is possible to assess the level of perfection of the production system in the form of probability distribution of states of risk at the enterprise (Table 3).

Table 3

Probability distribution of states of risk at the enterprise based on a questionnaire survey (December, 2014)

\begin{tabular}{|c|c|c|c|c|c|}
\hline \multirow{2}{*}{$\begin{array}{c}\text { Number } \\
\text { of step }\end{array}$} & \multicolumn{4}{|c|}{ Probabilities of states of risk at the enterprise } \\
\cline { 2 - 6 } & $\mathrm{p} 1(\mathrm{k})$ & $\mathrm{p} 2(\mathrm{k})$ & $\mathrm{p} 3(\mathrm{k})$ & $\mathrm{p} 4(\mathrm{k})$ & $\begin{array}{c}\text { Sum pi(k) } \\
\text { by steps }\end{array}$ \\
\hline 0 & 0 & 0 & 1 & 0 & 1,0 \\
\hline 5 & 0,08 & 0,38 & 0,29 & 0,25 & 1,0 \\
\hline 10 & 0,14 & 0,36 & 0,28 & 0,22 & 1,0 \\
\hline 30 & 0,14 & 0,36 & 0,29 & 0,21 & 1,0 \\
\hline
\end{tabular}

The data defined by the questionnaire survey about the probability distribution of states of risk reflect the existing level of technological maturity of the enterprise [4]. These results allow us to define transition probabilities of a Markov chain [18]. We shall note that in the case of projects implementation and production improvement, the assessment of risk level by employees will also be reflected in the questionnaire data.

5. 3. Comparison of the obtained experimental data with the results of simulation using the developed model of a Markov chain

Transition probabilities in the Markov chain were determined by experts who took into account the peculiarities of operation at the enterprise Geleka-M. Results that are given in Fig. 3 demonstrate that there is an urgent need for the initiation and implementation of a number of projects for creating normative (comfortable) conditions of safe work for the staff of the enterprise.

The matrix of transition probabilities of the system is determined by experts:

$$
\left\|\pi_{\mathrm{i} . \mathrm{j}}\right\|_{0}=\left\|\begin{array}{cccc}
0,75 & 0,15 & 0,1 & 0 \\
0,1 & 0,65 & 0,25 & 0 \\
0 & 0,25 & 0,45 & 0,3 \\
0 & 0,15 & 0,25 & 0,6
\end{array}\right\| .
$$

The level of perfection of production system in the coordinates of the enterprise risk assessments can be explored over several steps, shown in 30 steps for the system development trajectory in Fig. 3 where solid lines reflect results of the simulation, while bullets mark experimental data (Table 3), obtained when surveying the staff at the enterprise Geleka-M.

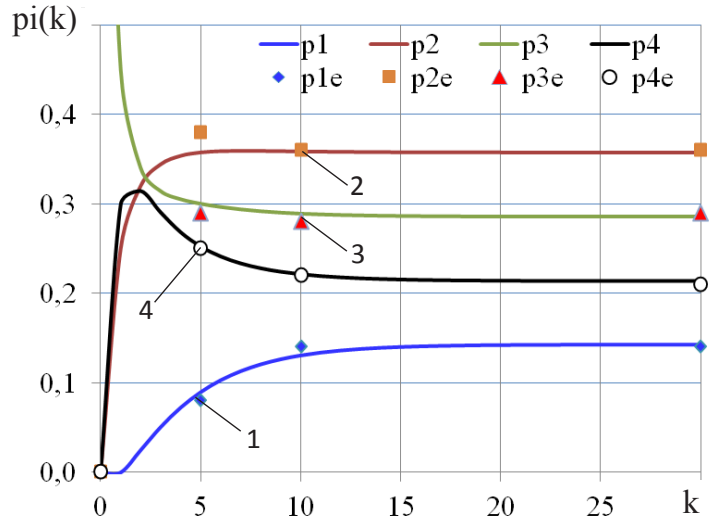

Fig. 3. Comparison of experimental data by questioning and results of the simulation in the coordinates of estimates of the degree of risk $\mathrm{p}_{\mathrm{i}}(\mathrm{k})$ and steps $\mathrm{k}$ : 1 - low risk; 2 - medium risk; 3 - high risk; 4 - extreme risk; $\mathrm{pNe}\{\mathrm{N}=1,2,3,4\}$ are experimental data

Constructing by transition probabilities (4) using a model for the trajectory of development of production system and the representation of actual data allow us to draw a conclusion on reliability of simulation data. The production system is in the region of medium risk (Fig. 3). To improve the general level of safety at this enterprise, it is necessary to improve organizational component in the activities that deal with labor safety.

\section{Development of information-management system for controlling the initiation of projects using a Markov model}

The enterprise "Geleka-M" cultivates and produces champignons. The number of employees is 180 . The initiator of projects is the Department of Labor Safety and Environment Protection. A list of recommended measures on labor safety is discussed at the general meetings of the enterprise staff, which is included in the employment contract between the enterprise and the labor collective.

A basic management scheme includes the following elements: 
- temporary organizational structure (board) of the project at the stage of initiation (project, project team, project environment, project's customer);

- a set of normative documents;

- staff of the enterprise;

- methods for working out the type of measures for improving the activities focused on ensuring safety of staff or aimed at improving working conditions (Fig. 4).

Represented basic diagram of managing the initiation of projects reflect significant differences in comparison with existing approaches. Generally, the activities concerning the implementation of projects (measures) on labor safety has a local nature. That is, projects are carried out without direct orientation towards specific result to improve the level of technological excellence. A formalization of processes we performed with the construction of a general basic management scheme will allow scientific substantiation for assessing effectiveness of the projects. An improvement in instrumental provision of the initiation of projects is implemented by the introduction of a Markov model into the control loop.

\section{Results of assessing efficiency of the initiation and implementation of projects}

As is known, the existing distribution in the probabilities of states of the system, which is described by a Markov chain, depends on the defined values of transition probabilities, which actually transform the level of technological maturity of the enterprise or organization into tolerance to changes [18]. This distribution for the enterprise Geleka-M, obtained by using the devised Markov model and confirmed by data of the natural production test, is shown in Fig. 3. As can be seen, the production risk assessment in 2014 may be attributed to category p 2 - medium risk. We established this tendency for a sustainable state of the system in steps $\mathrm{k}>10$ : p2 $>$ p $3>$ p $4>$ p1. Usually, such a characteristic of the system is not satisfactory, since probability p1 - of low risk - has the lowest value. It is necessary to perform certain changes in the system to improve the situation.
Managing the production system can be achieved through those projects that will change the situation that exists.

In early 2015, some activities were conducted for the initiation of certain projects that were included in the strategic plan of the enterprise. The following major projects were implemented throughout 2015:

- Development and implementation of the project of ventilation in production premises.

- Installing a thermal curtain at the incoming/outgoing gate of the workshop.

- Reworking and updating of new variants of job descriptions.

- Implementation of the project on the systematic training of the staff at the enterprise and testing the knowledge on labor safety.

- Modernization of premises for sanitary needs of the employees.

- Providing the workers with means of individual protection.

In the beginning of 2016, there was an attempt at assessing results of the implemented projects using a Markov model. The transition probabilities were determined by the method of questioning (see 5. 2). We received the following matrix of transition probabilities:

$$
\left\|\pi_{\mathrm{ij}}\right\|=\left\|\begin{array}{cccc}
0,75 & 0,1 & 0,15 & 0 \\
0,35 & 0,5 & 0,15 & 0 \\
0 & 0,4 & 0,5 & 0,1 \\
0 & 0,1 & 0,1 & 0,8
\end{array}\right\| .
$$

Simulation results with these transition probabilities represent new position of the organizational-technical system (Fig. 4).

As can be seen from Fig. 5 , the sum of values $\mathrm{p} 1+\mathrm{p} 2=0,67$ in step $\mathrm{k}=30$ grew larger, reflecting substantial improvement in the evaluation by personnel of activities on labor safety. This improvement is due to the reduced share of workers who assess the risk as high p3 (from $28.6 \%$ to $22.2 \%$ ) and of those who evaluate the risk as extreme p4 (from $22.4 \%$ to $10.1 \%)$

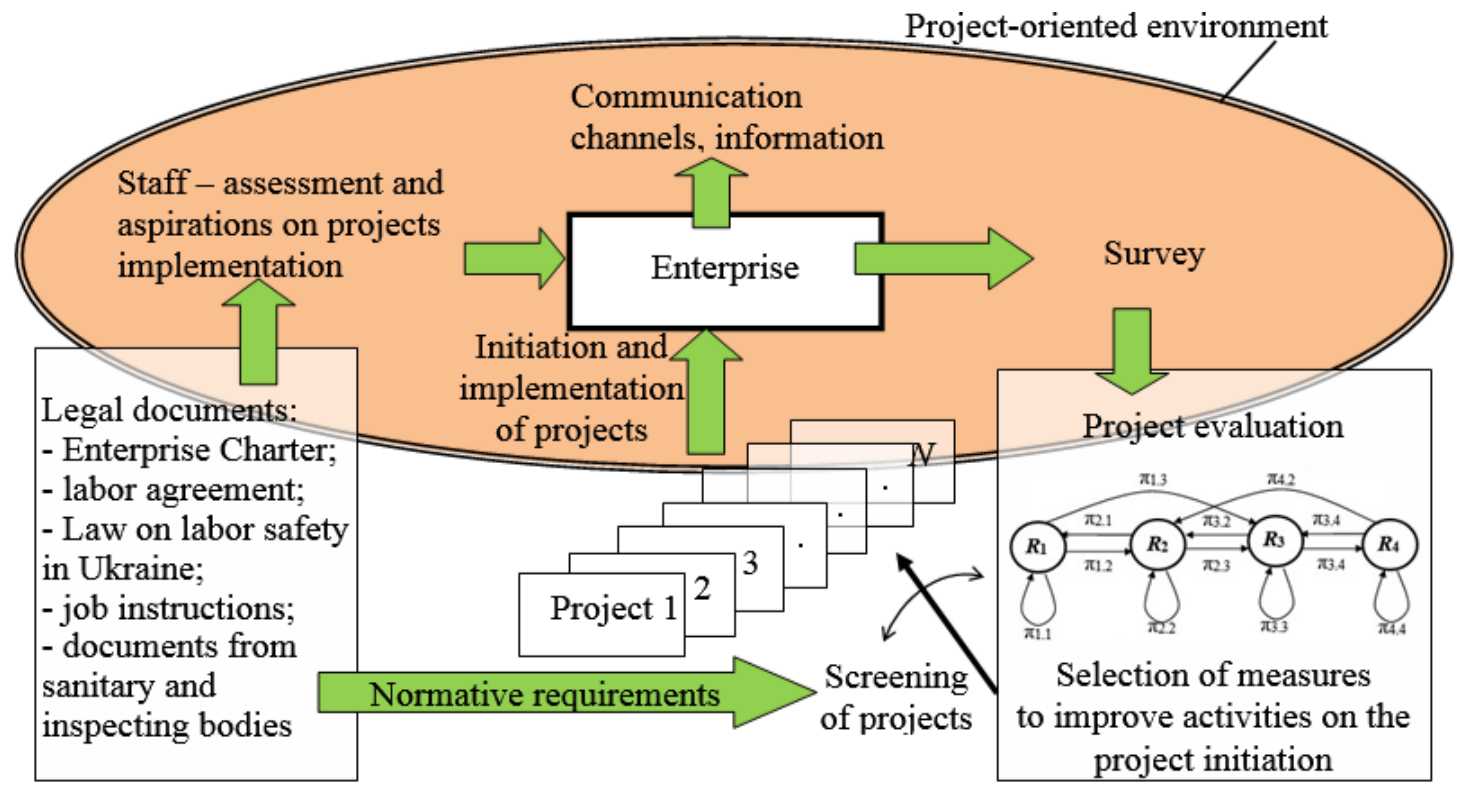

Fig. 4. Basic diagram of managing the initiation of projects 
With regard to these data, the implemented projects can be considered successful by the overall score. However, this does not mean that nothing else should be done. As the simulation results, obtained using a Markov model, demonstrate, in the organizational-technical system of the enterprise the sum of $\mathrm{p} 3+\mathrm{p} 4=32.3 \%$ reflects possible reserves to improve activities aimed at reducing the level of hazard. The system is continuously developing, which leads to the continuous changes in the indicators of risk. In addition, it should be noted that the described projects were actually implemented under conditions when other players did nothing to improve working conditions and thus to provide for a resistance to obtaining positive results of the projects as a means to attract the best employees and contribute to staff turnover.

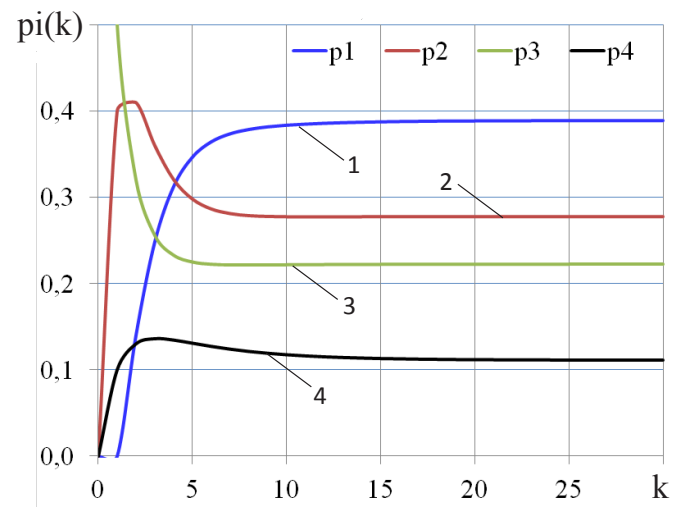

Fig. 5. Results of the new probability distribution of states of the production system in the coordinates of estimates of the degree of risk $p_{i}(k)$ and steps $k$ : 1 - low risk; 2 - medium risk; 3 - high risk; 4 - extreme risk

\section{Discussion of results of the implementation of a system for the initiation of projects}

In the practical implementation of the management system for the initiation of projects on labor safety (on the example of enterprise "Geleka-M"), the basic contradictions of this activity were revealed:

- result of activity on the initiation of the projects is determined in the external environment, not localized within the production area or a workshop;

- the system, which is made up of workshops of the enterprise, and the external environment is a weakly structured system - there are too many links, standards, structural features, rules, customs and traditions in it, as well as purely human relations, which are quite difficult to take fully into account;

- often it is almost impossible to receive feedback in order to assess effectiveness of specific measures aimed at creating safe working conditions at the enterprise;

- there is a need to overcome the resistance of middle managers at the enterprise to top management policy to conducting projects for improving working conditions; it is a common phenomenon in the production environment as a consequence of assumed concept about this activity as inefficient - "you should not change what is functioning".

The indicated objective and subjective factors form the field of interests and contradictions that have to be taken into account when initiating the projects.
Theoretical part of the study is based on the hypothesis that the degree of perfection in any production system can be represented by using a generalized indicator of the system quality, which corresponds to the level of risk that exists at the object. We understand risk to be the level of uncertainty of events or conditions whose occurrence negatively or positively affects the goals of activities [17]. The results obtained do not contradict the accepted hypothesis. It is demonstrated that the level of risk that exists at the object can be determined by using the survey of the employees. A phenomenological reflection for the assessment of degree of perfection for different systems is a Markov chain. It is proven that the use of Markov chains is applicable to reflect the properties of production systems about the degree of perfection of a production system.

Research results may serve as a basis for the creation of models of management objects that contain its organizational structure and reflect parametric properties of the system for obtaining information needed for decision making regarding the initiation of projects. The devised method of building information management system to control the process of initiating projects, where a Markov model is a part of the control loop, might make a contribution into development of activities related to enhancing technological maturity of organizations in the field of project management.

\section{Conclusions}

The study was conducted as a theoretical basis for the substantiation of a general basic management scheme of the project initiation.

1. We devised a model for estimating the level of perfection of organizational-technical system based on a uniform Markov chain with discrete time and states that reflect the degree of risk in the system: $R_{1}-$ low risk, $R_{2}-$ medium risk, $\mathrm{R}_{3}$ - high risk, $\mathrm{R}_{4}$ - extreme risk. It is proved that the trajectory of development of a production system allows drawing a conclusion about reliability of simulation data. It is shown that at first production system is in the region of medium risk. To improve the general level of safety at the given enterprise, it is necessary to improve organizational component in the activity that deals with labor safety.

2. We developed a method for the identification of a Markov model by using a method of direct measurement of probabilities in the states of the system by questionnaire survey that allows "tuning" a Markov chain to represent the properties of a specific object. We proposed practical recommendations as for determining the sample size - number of questionnaires, which provide for the selected accuracy of measurements. It is demonstrated that the minimum sample size does not exceed 90 surveys. In this case, at confidence probability $\mathrm{p}_{\mathrm{d}}=0.95$, error of determining the values of transition probabilities would not exceed $0.75 \%$. This magnitude is absolutely acceptable.

3. We proposed a structure of the information-management system to control the process of project initiation, in which a Markov model is part of the control loop. The key process that creates conditions for the practical implementation of information -management systems is to determine values of transition probabilities of a Markov chain through the technique of questioning.

4. We examined practical aspects of assessing effectiveness of the initiation and implementation of projects under 
conditions of existing enterprise. An evaluation of results of changing the probability distribution in the states of production system in the coordinates of estimates of the degree of risk during the year of the study demonstrated significant improvement in the evaluation by personnel of the activities that addressed labor safety. This improvement occurred due to a decreasing share of workers who assessed the risk as high (from $28.6 \%$ to $22.2 \%$ ) and those who evaluated the risk as extreme (from $22.4 \%$ to $10.1 \%$ ). Judging by these data, the executed projects may be considered successful.

In the present study we resolved a relevant task on the formalization, improvement and implementation of methodological and instrumental techniques for managing the project initiation.

\section{References}

1. Tchiehe, D. N. Classification of risk acceptability and risk tolerability factors in occupational health and safety [Text] / D. N. Tchiehe, F. Gauthier// Safety Science. - 2017. - Vol. 92. - P. 138-147. doi: 10.1016/j.ssci.2016.10.003

2. Moskaliuk, A. Yu. Modeling the occupational health projects initiation using Markov chains [Text] / A. Yu. Moskaliuk, V. D. Gogunskii, V. M. Purich // Technology audit and production reserves. - 2016. - Vol. 3, Issue 2 (29). - P. 35-39. doi: 10.15587/23128372.2016 .71834

3. Lukianov, D. V. Priority projects of social orientation in a competitive environment [Text] / D. V. Lukianov, K. V. Kolesnikova, K. M. Dmitrenko // Management of development of complex systems. - 2015. - Issue 23 (1). - P. 62-68.

4. Turner, J. P. Manual on project-oriented management [Text] / J. P. Turner. - Moscow: Publishing Grebennikov House, 2007. - 552 p.

5. Stanovskii, O. L. Dynamic models in the method of project management [Text] / O. L. Stanovskii, K. V. Kolesnikova, O. Yu. Lebedeva, H. Ismail // Eastern-European Journal of Enterprise Technologies. - 2015. - Vol. 6, Issue 3 (78). - P. 46-52. doi: 10.15587/17294061.2015.55665

6. Van der Hoorn, B. Playing projects: Identifying flow in the 'lived experience' [Text] / B. Van der Hoorn // International Journal of Project Management. - 2015. - Vol. 33, Issue 5. - P. 1008-1021. doi: 10.1016/j.ijproman.2015.01.009

7. Bushuyev, S. Proactive Program Management for Development National Finance System in Turbulence Environment [Text] / S. Bushuyev, R. Jaroshenko // Procedia - Social and Behavioral Sciences. - 2013. - Vol. 74. - P. 61-70. doi: 10.1016/ j.sbspro.2013.03.044

8. Kolesnikova, K. V. The development of the theory of project management: project initiation study law [Text] / K. V. Kolesnikova // Management of development of complex systems. - 2014. - Issue 17. - P. 24-30. - Available at: http://journals.uran.ua/ urss/article/view/38688/35053

9. Olekh, T. M. Matrix diagram and the "strong connection" indicator value in the projects [Text] / T. M. Olekh, K. V. Kolesnikova // Electrical and Computer Systems. - 2012. - Issue 7. - P. 148-153.

10. Gogunskii, V. "Lifelong learning" is a new paradigm of personnel training in enterprises [Text] / V. Gogunskii, A. Kolesnikov, K. Kolesnikova, D. Lukianov // Eastern-European Journal of Enterprise Technologies. - 2016. - Vol. 4, Issue 2 (82). - P. 4-10. doi: 10.15587/1729-4061.2016.74905

11. Chernega, Yu. S. Development of activity model of labor safety engineer using Markov chains [Text] / Yu. S. Chernega, V. D. Gogunsky // Eastern-European Journal of Enterprise Technologies. - 2014. - Vol. 5, Issue 3 (71). - P. 39-43. doi: 10.15587/1729-4061.2014.28016

12. Sherstyuk, O. The research on role differentiation as a method of forming the project team [Text] / O. Sherstyuk, T. Olekh, K. Kolesnikova // Eastern-European Journal of Enterprise Technologies. - 2016. - Vol. 2, Issue 3 (80). - P. 63-68. doi: 10.15587/ 1729-4061.2016.65681

13. Bushuyev, S. D. Convergence of knowledge in project management [Text] / S. D. Bushuyev, D. A. Bushuyev, V. B. Rogozina, O. V. Mikhieieva // 2015 IEEE 8th International Conference on Intelligent Data Acquisition and Advanced Computing Systems: Technology and Applications (IDAACS). - 2015. doi: 10.1109/idaacs.2015.7341355

14. Rudenko, S. V. Development of the Markov model state changes in patients projects providing medical services [Text] / S. V. Rudenko, M. V. Romanenko, O. G. Katunina, K. V. Kolesnikova // Management of development of complex systems. 2012. - Issue 12. - P. 86-90. - Available at: http://journals.uran.ua/urss/article/view/41121/37470

15. Yastrebenetsky, M. A. Safety of nuclear power stations. Information and control systems [Text] / M. A. Yastrebenetsky, V. I. Vasilchenko, S. V. Vinogradskaya et. al. - Kyiv: Publishing by Technscs, 2004. - 472 p.

16. Kolesnikova, K. V. Modeling of semistructured project management systems [Text] / K. V. Kolesnikova // Odes'kyi Politechnichnyi Universytet. Pratsi. - 2013. - Issue 3 (42). - P. 127-131. doi: 10.15276/opu.3.42.2013.25

17. A guide to the project management body of knowledge (PMBOK guide) [Text]. - 5-th ed. - USA: Project Management Institute, 2013. -619 p.

18. Rudenko, S. V. Implementation of the project management of the institution's image in the realities of China [Text] / S. V. Rudenko, F. Ma, S. M. Glowatska, K. V. Kolesnikova // High Technology in Machine build. - 2015. - Issue 1 (25). - P. 141-159.

19. ISO 21500:2012. Guidance on project management [Text]. - ISO PC 236. - 2012. - \# 113. - 51 p. 